\title{
LAB-SCALE COLUMN STUDY ON PHOSPHORUS REMOVAL FROM SYNTHETIC WASTEWATER BY FILTRALITE P AND IRON FILINGS
}

\author{
Ala Kirjanova ${ }^{1}$ \\ Mindaugas Rimeika ${ }^{2}$ \\ Kristina Zopelyt $\dot{e}^{3}$ \\ ${ }^{1,2}$ Vilnius Gediminas Technical University, Lithuania \\ ${ }^{3} U A B$ "Sweco", Lithuania
}

\begin{abstract}
Column study was performed in order to compare phosphate phosphorus ( $\left.\mathrm{PO}_{4}-\mathrm{P}\right)$ removal capacity of iron filings and Filtralite $P$. The experiment with two vertical downflow columns (0.05 in diameter and with $0.9 \mathrm{~m}$ medium height) feeding synthetic wastewater was carried out over a period of 66 days at wastewater temperature of $17.2-21.8^{\circ} \mathrm{C}$. The study also aimed to determine the effect of submergence of the medium on Filtralite $P \mathrm{PO}_{4}-\mathrm{P}$ removal potential. During the experiment the submerged Filtralite $P$ sorbed almost double amount of $\mathrm{PO}_{4}-\mathrm{P}$ (1581 mg PO $4-\mathrm{P} / \mathrm{kg}$ filter material or $662 \mathrm{mg} \mathrm{PO} 4-\mathrm{P} / \mathrm{m}^{3}$ filter material) compared to the unsubmerged $\left(881 \mathrm{mg} \mathrm{PO} 4-\mathrm{P} / \mathrm{kg}\right.$ filter material or $369 \mathrm{mg} \mathrm{PO} 4-\mathrm{P} / \mathrm{m}^{3}$ filter material). In both cases $\mathrm{PO}_{4}-\mathrm{P}$ removal efficiency exceeded $90 \%$ when $\mathrm{pH}$ in the effluent was higher than 9.5. Through the experimental period the iron filings removed $2249 \mathrm{mg} \mathrm{PO} 4 \mathrm{P} / \mathrm{kg}$ filter material. When evaluating the amount of removed $\mathrm{PO}_{4}-\mathrm{P}$ per volume of filter material, the iron filings removed $2164 \mathrm{mg} \mathrm{PO}_{4}-\mathrm{P} / \mathrm{m}^{3}$ filter material, i. e. 3.3 times more than the submerged Filtralite $P$ did. In the case of iron filings the largest $\mathrm{PO}_{4}-\mathrm{P}$ amount was removed in the top layer $(0-30 \mathrm{~cm})$ of the filter material. The amount of removed $\mathrm{PO}_{4}-\mathrm{P}$ decreased and $\mathrm{PO}_{4}-\mathrm{P}$ removal efficiency increased with depth of the medium: in the top layer $(0-30 \mathrm{~cm}) \mathrm{PO}_{4}-\mathrm{P}$ removal efficiency was $27 \%$, whereas in the bottom layer $(60-90 \mathrm{~cm})$ it reached $44 \%$. The same tendency of $\mathrm{PO}_{4}-\mathrm{P}$ removal efficiency was observed in the column with the submerged Filtralite $P$; however, the $\mathrm{PO}_{4}-\mathrm{P}$ removal efficiency in all layers of this filter material was lower in comparison with the iron filings.
\end{abstract}

\section{KEYWORDS}

Wastewater, phosphorus removal, column experiment, Filtralite $P$, iron filings. 


\section{INTRODUCTION}

Phosphorus is a fundamental element for normal functioning of ecosystems. Nevertheless, excess amount of phosphorus in water may cause a process of euthrophication, therefore the quantity of phosphorus that comes into contact with surface waters must be controlled [1].

Keplinger et al. (2004) [2] estimated that biological phosphorus removal by activated sludge and chemical phosphorus removal by application of reagents is not profitable for small communities. The alternative way of phosphorus removal is to use materials which compose of elements that could bind phosphorus. The scientists have investigated phosphorus removal by using various materials such as sand, crushed marble, vermiculite, calcite, limestone, alunite, shellsand, Filtralite P, Polonite, Nordkalk Filtra P, wollastonite, alum, blast furnace slag, electric arc furnace slag, ochre, iron filings [3-20]. These materials are divided into three groups: natural materials, industrial by-products and man-made sorbents [1, 21-23].

When phosphorus is removed using substrates, the phosphate phosphorus reacts with calcium, magnesium, iron and aluminium ions present in the substrate and forms insoluble compounds. Phosphorus removal capacity of man-made sorbents (e.g. Filtralite P, Polonite, Nordkalk Filtra $P$ ) is normally 10-100 times higher than the one of natural materials or industrial byproducts [1]. On the other hand, an efficient substrate for phosphorus removal must not only possess a high sorption capacity but also have adequate hydraulic conductivity, physical chemical characteristics, recycling potential, reasonable cost and be locally available [24].

In real wastewater treatment systems, especially in Scandinavian countries, man-made sorbents Filtralite $P$ and Nordkalk Filtra $P$ are mostly used [22]. Filtralite $P$ is particularly popular in Norway, the producing country. In Norway this substrate is usually used as a filter material in constructed wetlands [3]. Filtralite $P$ has a high calcium and magnesium oxides $(\mathrm{CaO}$ and $\mathrm{MgO})$ content. Exposed to water, these oxides form calcium and magnesium hydroxides, which, at certain $\mathrm{pH}$ value, split into $\mathrm{Ca}^{2+}$ and $\mathrm{Mg}^{2+}$ and these ions precipitate phosphorus [25]. There are some advantages of Filtralite $P$ to be distinguished:

- high phosphorus sorption capacity measured in laboratory tests - Jenssen and Krogstad (2003) [26] have evaluated that Filtralite $P$ phosphorus sorption capacity can reach up to $12 \mathrm{~g}$ $\mathrm{P} / \mathrm{kg}$ filter material;

- the phosphorus saturated filter material can be used as a fertilizer in agriculture sector;

- high hydraulic conductivity;

- the substrate is highly studied with batch, column and field tests [24].

On the other hand, when using Filtralite $P$ for phosphorus removal, $\mathrm{pH}$ in effluents can exceed the permitted discharge value and acidification or additional treatment of treated wastewater could be required. Moreover, Filtralite $P$ is criticised for the high energy demand that the production processes consume and also for fairly high costs $[1,24]$.

Materials which remove phosphorus mostly by the interaction of the latter with iron present in the material are poorly studied. Kang et al. (2003) [27] have investigated phosphorus removal from secondary effluent by using laboratory produced minerals ferrihydrite, goethite and hematite. Heal et al. (2003) [10] have studied phosphorus removal from wastewater by ochre - a by-product from mine water treatment. Choung and Jeon (2000) [28] applied a method of anaerobic microbial corrosion for phosphorus removal. The principle of this method is that iron (iron nuts immersed in water, in this particular case) oxidizes when 
exposed to the activity of sulphate-reducing bacteria. During the oxidation process ferric oxides are released, and then ferric oxides join phosphates to form slightly soluble compounds. Rolf et al. (1998) [19] and Burde et al. (2001) [6] have investigated the use of iron filings for phosphorus removal. The iron filings are a by-product of steel processing. The use of iron filings in wastewater treatment should be encouraged as a good practice model for the re-use of waste.

The objective of this study is to compare phosphate removal capacity of iron filings and Filtralite $P$ during the column study and to evaluate phosphate sorption at different column heights. The study also aims to determine the effect of submergence of the medium on Filtralite $P$ phosphate removal potential.

\section{MATERIALS AND METHODS}

The experimental set-up (Figure 1) consisted of two analogous structure vertical downflow columns filled with different filter medium - F1 (column with iron filings) and F2 (column with Filtralite P), two wastewater storage tanks (1 and 2) and a pump (3). During the tests the raw wastewater was stored in the bottom wastewater storage tank (1) from which it was transported to the upper wastewater storage tank (2) via the pump (3). From the upper storage tank the wastewater flowed by gravity into both columns, while even distribution of the influent was controlled by valves (4). The inner diameter of both columns was $5 \mathrm{~cm}$, the height of the filter medium in the columns was $90 \mathrm{~cm}$, thus the volume of both media was 1.8 l. The columns had interjacent wastewater sampling ports (6) that enabled sampling from different column height levels.

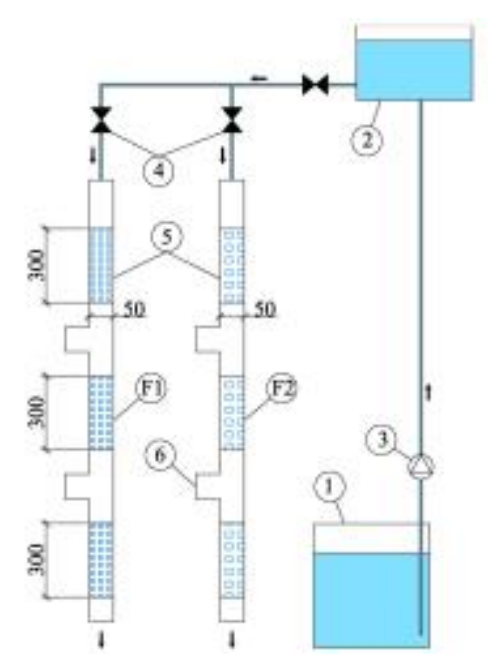

Figure 1. The schematic diagram of the experimental set-up: F1 - column with iron filings, F2 - column with Filtralite P, 1 - bottom wastewater storage tank, 2 - upper wastewater storage tank, 3 -pump, 4 -valve, 5-filter medium, 6 -wastewater sampling port 


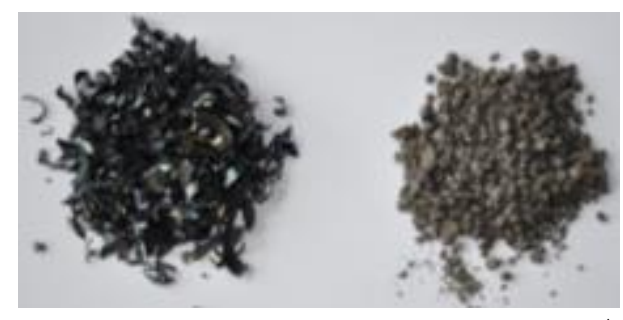

A

B

Figure 2. Tested media: A-iron filings, $B-$ Filtralite $P$

The column F1 was filled with $1.7 \mathrm{~kg}$ of iron fillings (Figure 2, A). The filings were of carbon steel (grade CT.45) and had the following chemical composition: $0.45 \%$ carbon, $0.17-0.37 \%$ silicon, $0.50-0.80 \%$ manganese, $<0.40 \%$ chromium, $<0.40 \%$ nickel, $<0.10 \%$ molybdenum, $<0.04 \%$ sulphur, $<0.04 \%$ phosphorus. The size range of iron filings particles was $0.5-20 \mathrm{~mm}$ and bulk density was $963 \mathrm{~kg} / \mathrm{m}^{3}$. The phosphate removal in the column with iron filings was based on chemical reactions - $\mathrm{PO}_{4}-\mathrm{P}$ removal occurred when ferric oxides, generated during the oxidation process of iron filings, reacted with phosphate ions, thus forming slightly soluble compounds.

For comparison in the column F2 $0.74 \mathrm{~kg}$ of man-made phoshorus sorbent Filtralite $P$ (Maxit AS, Norway) was used (Figure 2, B). The Filtralite $P$ consists of clay particles with a large specific surface area and a high porosity. It has a high $\mathrm{pH}$ and a high $\mathrm{Ca}$ and $\mathrm{Mg}$ content. The size range of tested Filtralite $P$ particles was $0.5-4 \mathrm{~mm}$. The Filtralite $P$ bulk density was $370 \mathrm{~kg} / \mathrm{m}^{3}$, particle density $910 \mathrm{~kg} / \mathrm{m}^{3}$, particle porosity $\sim 65 \%$, voids $\sim 60 \%, \mathrm{pH} 12$, alkalinity 35 mekv/l [29].

During the experiment iron filings were not submerged as oxygen was needed for the formation of ferric oxides. The column with iron filings was tested for 66 days. Aerobic conditions were not necessary when using Filtralite $P$ for phosphate removal, thus, the effect of Filtralite $P$ submergence on phosphate removal efficiency was analyzed during the experiment. For this purpose, the first half of the experiment (days 1-27) was run with the unsubmerged Filtralite $P$, while the second half of the experiment (days 28-54) was run with the submerged Filtralite $P$. In both cases the column with Filtralite $P$ was fed with wastewater until phosphate removal efficiency of the sorbent became 0 . When the filter medium was not submerged, the air to the columns was introduced by means of natural ventilation - the air circulated through columns inlet and outlet. When the medium was submerged, forced aeration was not applied.

The experimental set-up was fed with synthetic wastewater. It was prepared weekly by adding potassium hydrogen phosphate $\mathrm{KH}_{2} \mathrm{PO}_{4}$ into tap water. The characteristics of the wastewater fed to the columns are shown in Table 1 . The wastewater flow rate was regulated every day of sampling. The columns were in operation on working days 10 hours a day, every column was supplied with $1 \mathrm{l} / \mathrm{h}$ of wastewater. Under these conditions hydraulic surface loading rate was $0.5 \mathrm{~m}^{3} / \mathrm{m}^{2} / \mathrm{h}$.

During the first 54 days sampling of influent and effluent wastewater was done every working day. From day 55 (when the experiment was carried out only with the iron filings) the samples were taken twice a week. During the experiment days 32-44 seven samples were taken from each of interjacent sampling ports in order to analyze phosphate removal at different column height levels. All of the samples were grab samples and analyzed with 
respect to phosphate phosphorus $\left(\mathrm{PO}_{4}-\mathrm{P}\right), \mathrm{pH}$ and dissolved oxygen (DO) concentrations. Chemical wastewater analyses were done according to the following methods:

- phosphate phosphorus concentration $\left(\mathrm{PO}_{4}-\mathrm{P}\right)$ was measured by Spectroquant tests kits and Genesys $10 \mathrm{UV}$-Vis spectrophotometer (Thermo Fisher Scientific, USA);

- dissolved oxygen concentration (DO) and wastewater temperature were measured with oxygen meter Oxi 330/SET (WTW, Germany);

- $\mathrm{pH}$ was measured with $\mathrm{pH}-$ meter $\mathrm{pH} 330 i / S E T$ (WTW, Germany).

\begin{tabular}{lllll}
\hline & Average & Standard deviation & Lowest value & Highest value \\
\hline $\mathrm{PO}_{4}-\mathrm{P}, \mathrm{mg} / \mathrm{l}$ & 8.4 & 3.1 & 2.1 & 14.7 \\
\hline $\mathrm{pH}$ & 8.1 & 0.3 & 7.1 & 8.5 \\
\hline $\mathrm{DO}, \mathrm{mg} / \mathrm{l}$ & 8.2 & 0.4 & 7.3 & 8.7 \\
\hline Temperature, ${ }^{\circ} \mathrm{C}$ & 17.2 & 21.8 & - & - \\
\hline
\end{tabular}

Table 1. Characteristics of the wastewater fed to the columns

During the experiment $\mathrm{PO}_{4}-\mathrm{P}$ removal efficiency of both tested materials was calculated according to the following equation:

$$
E=\frac{C_{i n}-C_{e f}}{C_{i n}} \cdot 100,
$$

here $\mathrm{E}-\mathrm{PO}_{4}-\mathrm{P}$ removal efficiency, \%; $C_{i n}$ - concentration of $\mathrm{PO}_{4}-\mathrm{P}$ in the influent of the column, mg/l; $C_{\text {ef }}$ - concentration of $\mathrm{PO}_{4}-\mathrm{P}$ in the effluent of the column, mg/l.

The amount of $\mathrm{PO}_{4}-\mathrm{P}$ removed was calculated by the mass balance equation, assuming that the amount of removed $\mathrm{PO}_{4}-\mathrm{P}$ is equal to the difference between the amount of $\mathrm{PO}_{4}-\mathrm{P}$ in the influent and effluent of the column:

$$
M=\left(C_{i n}-C_{e f}\right) \cdot Q
$$

here $\mathrm{M}$ - amount of removed $\mathrm{PO}_{4}-\mathrm{P}, \mathrm{mg} / \mathrm{d} ; \mathrm{Q}$ - flow rate, $1 / \mathrm{d}$.

\section{RESULTS AND DISCUSSION}

$\mathrm{PO}_{4}-\mathrm{P}$ concentrations in the influent and effluent of the columns throughout the experimental period are shown in Figure 3. 


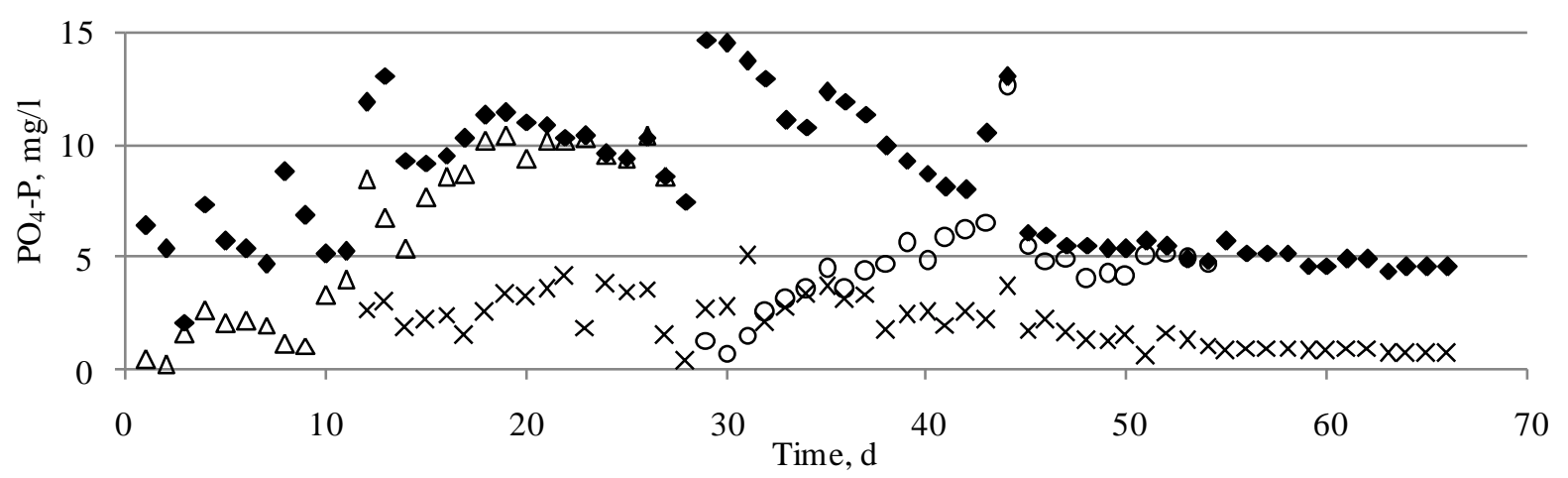

- Influent $\Delta$ unsubmerged Filtralite P - effluent $O$ Submerged Filtralite P - effluent $\times$ Iron filings - effluent

Figure 3. $\mathrm{PO}_{4}-\mathrm{P}$ concentration in the influent and effluent of the columns

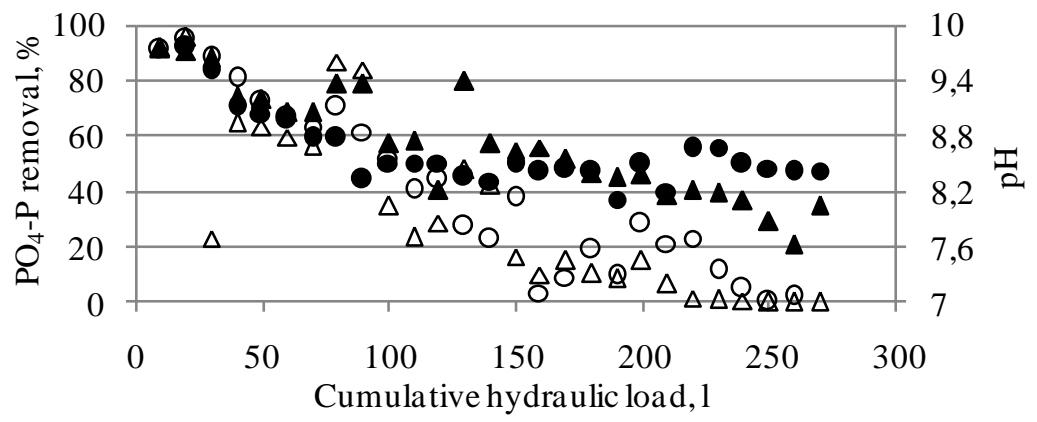

$\triangle$ PO4-P - unsubmerged Filtralite P O PO4-P - submerged Filtralite P

$\Delta$ pH - unsubmerged Filtralite $\mathrm{P} \quad \bullet \mathrm{pH}$ - submerged Filtralite $\mathrm{P}$

Figure 4. $\mathrm{PO}_{4}-\mathrm{P}$ removal efficiency and $\mathrm{pH}$ values in the effluent of the column with Filtralite $P$

Initially $\mathrm{PO}_{4}-\mathrm{P}$ concentration in the effluent was low in both cases: firstly, in the case of the unsubmerged Filtralite $P$ and, secondly, in the case of the submerged Filtralite $P$. In both cases $\mathrm{PO}_{4}-\mathrm{P}$ concentration increased gradually with time until it became equal to the $\mathrm{PO}_{4}-\mathrm{P}$ concentration in the influent. It might be seen from Figure 4 that Filtralite $P$ PO $4-\mathrm{P}$ removal efficiency decreased over time as well as $\mathrm{pH}$ value in the effluent. In both cases initial $\mathrm{pH}$ value in the effluent was 9.8, however it decreased gradually to 7.6 in the case of the unsubmerged Filtralite $P$ and 8.4 in the case of the submerged Filtralite $P$. Whereas, in the effluent of the column with iron filings the $\mathrm{pH}$ remained stable at the value of $8.8 \pm 0.2$ (Table 2).

The $\mathrm{pH}$ of the Filtralite $P$ medium is high due to calcium ions that react and bind phosphate ions. The experiments carried out by Adam et al. (2007) [3] using a column with Filtralite $P$ and synthetic wastewater also had the same results: a gradual decrease in the effluent $\mathrm{pH}$. The authors affirm that it must be a consequence of the calcium ions loss in the medium as it was also observed during the experiment. Figure 5 shows the correlation between Filtralite $P \mathrm{PO}_{4}-$ $\mathrm{P}$ removal efficiency and the effluent $\mathrm{pH}$. It can be seen that $\mathrm{PO}_{4}-\mathrm{P}$ removal efficiency was higher than $90 \%$ when the effluent $\mathrm{pH}$ exceeded 9.5 . 


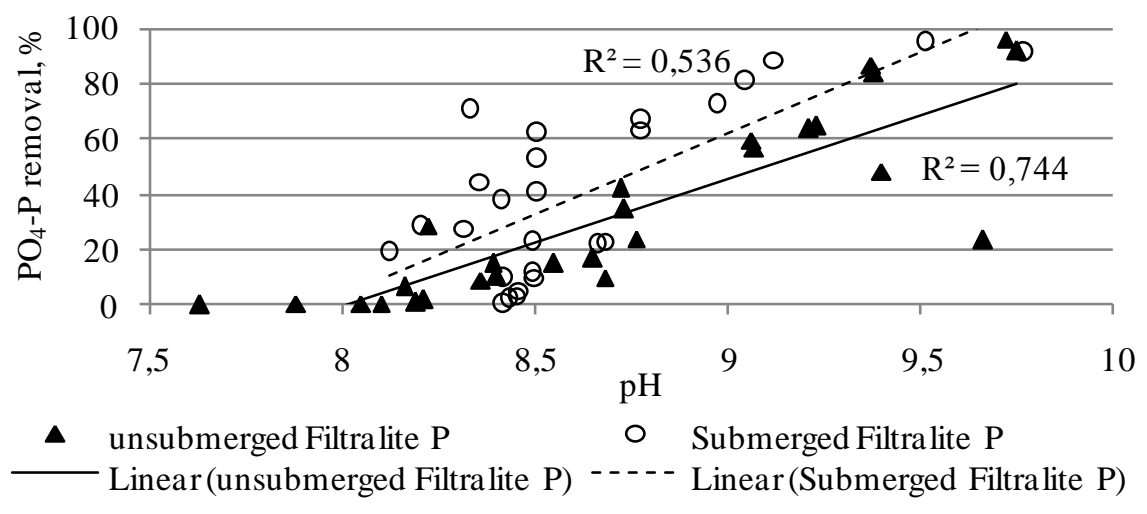

Figure 5. Correlation between the effluent $\mathrm{pH}$ and Filtralite $\mathrm{P} \mathrm{PO}_{4}-\mathrm{P}$ removal efficiency

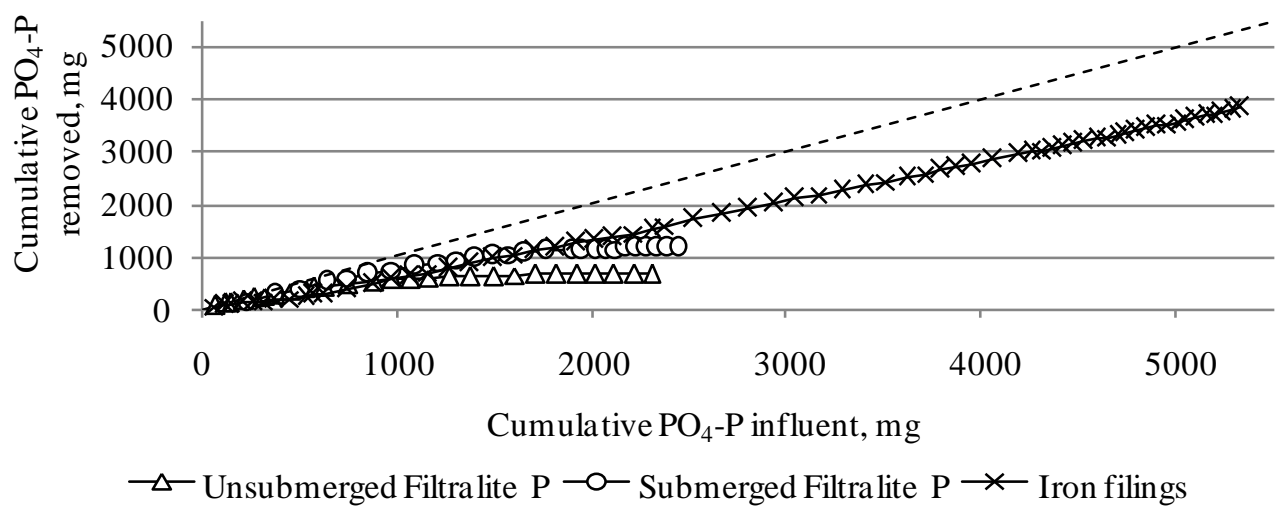

Figure 6. The cumulative amount of $\mathrm{PO}_{4}-\mathrm{P}$ fed to the columns and the cumulative amount of $\mathrm{PO}_{4}-\mathrm{P}$ removed

\begin{tabular}{lll}
\hline & $\mathrm{DO}, \mathrm{mg} / \mathrm{l}$ & $\mathrm{pH}$ \\
\hline Influent & $8.2 \pm 0.4$ & $8.1 \pm 0.3$ \\
\hline Filtralite $P$ - unsubmerged & $8.0 \pm 0.2$ & $8.7 \pm 0.6$ \\
\hline Filtralite $P$ - submerged & $8.4 \pm 0.2$ & $8.6 \pm 0.4$ \\
\hline Iron filings & $7.2 \pm 0.6$ & $8.8 \pm 0.2$ \\
\hline
\end{tabular}

Table 2. DO and pH values in the influent and effluent of the columns

In Figure 6 the cumulative amount of $\mathrm{PO}_{4}-\mathrm{P}$ removed is compared to the cumulative amount of $\mathrm{PO}_{4}-\mathrm{P}$ fed to the columns. Dashed line represents the case when the entire amount of $\mathrm{PO}_{4}-\mathrm{P}$ fed is removed by the substrate. It can be seen that the submerged Filtralite $P$ sorbs more $\mathrm{PO}_{4}-\mathrm{P}$ than the unsubmersed substrate. However, in both cases Filtralite $P$ gradually sorbs less $\mathrm{PO}_{4}-\mathrm{P}$ and $\mathrm{PO}_{4}-\mathrm{P}$ sorption curves in Figure 6 become horizontal. On the other hand, it is clear that while the Filtralite $P$ almost did not sorbed $\mathrm{PO}_{4}-\mathrm{P}$, the iron filings kept on removing it successfully. 
Table 2 shows that in the column with the Filtralite $P$ DO concentration in the effluent was equal to the DO concentration in the influent. However, in the column with iron filings the DO concentration in the effluent was lower than in the influent. It is supposed that the decrease of DO concentration is related to the reaction between the iron ions in iron filings and the oxygen in the wastewater forming ferric oxides as a result.

From Figure 7 it is seen that $\mathrm{PO}_{4}-\mathrm{P}$ removal process in the column with iron filings was stable when the $\mathrm{PO}_{4}-\mathrm{P}$ volumetric load was in the range of $2.5-8.3 \mathrm{~g} \mathrm{PO}_{4}-\mathrm{P} / \mathrm{m}^{3} / \mathrm{h}$. With the increasing $\mathrm{PO}_{4}-\mathrm{P}$ load, the concentration of $\mathrm{PO}_{4} \mathrm{P}$ in the effluent also increased, although $\mathrm{PO}_{4}-\mathrm{P}$ removal efficiency was stable and ranged from 60 to $95 \%$. The average $\mathrm{PO}_{4}-\mathrm{P}$ removal efficiency of the iron filings througout the experiment was $69 \pm 16 \%$ and the average $\mathrm{PO}_{4}-\mathrm{P}$ concentration in the effluent was $2.4 \pm 1.1 \mathrm{mg} / \mathrm{l}$.

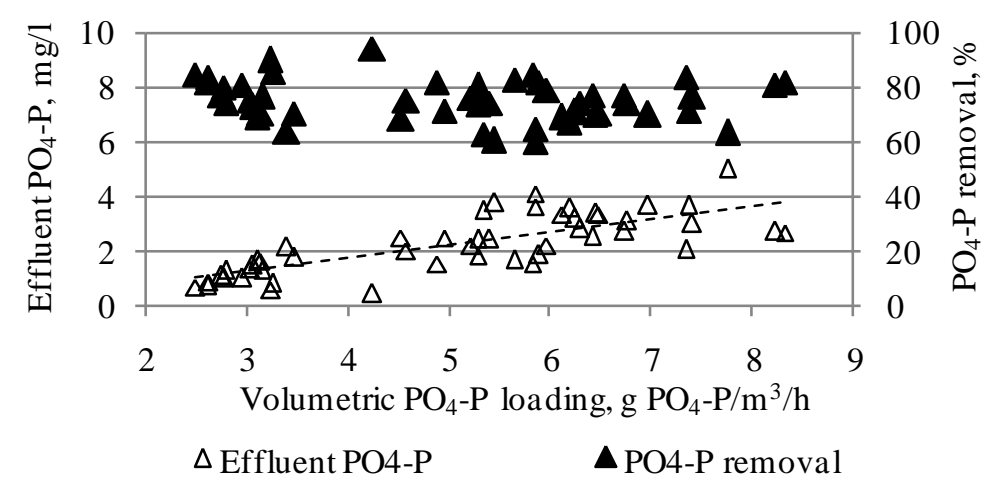

Figure 7. Effect of the volumetric $\mathrm{PO}_{4} \mathrm{P}$ loading on $\mathrm{PO}_{4} \mathrm{P}$ concentration in the effluent and removal efficiency of iron filings

\begin{tabular}{llll}
\hline & \multicolumn{2}{c}{ Filtralite $^{1}$} & Iron filings $^{2}$ \\
\cline { 2 - 3 } & Unsubmerged & Submerged & \\
\hline Days of operation & 26 & 26 & 66 \\
\hline Amount of fed wastewater, 1 & 260 & 260 & 660 \\
\hline $\mathrm{PO}_{4}-\mathrm{P}$ load, $\mathrm{g}$ & 2217 & 2392 & 5330 \\
\hline Removed $\mathrm{PO}_{4}-\mathrm{P}, \mathrm{mg}$ & 652 & 1170 & 3823 \\
\hline Removed $\mathrm{PO}_{4}-\mathrm{P}, \mathrm{mg} \mathrm{PO} 4-\mathrm{P} / \mathrm{kg}$ filter material & 881 & 1581 & 2249 \\
\hline Removed $\mathrm{PO}_{4}-\mathrm{P}, \mathrm{mg} \mathrm{PO}$-P $/ \mathrm{m}^{3}$ filter material & 369 & 662 & 2164 \\
\hline
\end{tabular}

${ }^{1}$ Values showed in the table are obtained until the moment when $\mathrm{PO}_{4}-\mathrm{P}$ removal efficiency became 0 .

${ }^{2}$ Values showed in the table are obtained throughout the entire experimental period.

Table 3. Amounts of removed $\mathrm{PO}_{4}-\mathrm{P}$

The amounts of $\mathrm{PO}_{4}-\mathrm{P}$ removed by both filter materials are shown in Table 3 . The calculation of the $\mathrm{PO}_{4}-\mathrm{P}$ amounts sorbed by Filtralite $P$ includes phosphorus amounts sorbed until the $\mathrm{PO}_{4}-\mathrm{P}$ removal efficiency became 0 . Meanwhile the calculation of the $\mathrm{PO}_{4} \mathrm{P}$ amounts removed by iron filings includes phosphorus amounts removed throughout the entire experimental period. At the end of the experimental period $\mathrm{PO}_{4}-\mathrm{P}$ removal efficiency of the iron filings was still high. In case the experiment continued, the iron filings would continue 
$\mathrm{PO}_{4}-\mathrm{P}$ removal from wastewater during a certain period of time and amount of removed $\mathrm{PO}_{4}-$ $\mathrm{P}$ would be even larger.

From Table 3 it is seen that Filtralite $P$ sorbs almost double amount of $\mathrm{PO}_{4}-\mathrm{P}$ when it is submerged in wastewater than when it is not. In the column experiment by Adam et al. (2007) [3] submerged Filtralite $P$ sorbed $497 \mathrm{mg} \mathrm{PO} 4-\mathrm{P} / \mathrm{kg}$ material, which is 3 times less than in the experiment presented in this paper. This difference can be associated with variations in the experimental set-up such as $\mathrm{PO}_{4}-\mathrm{P}$ concentration, hydraulic loading rate, structure of the column [24]. During the experiments by Adam et al. (2007) [3] the column of $0.14 \mathrm{~m}$ diameter was fed with $5.5 \mathrm{l} / \mathrm{d}$ wastewater flow rate. Through the experiment described in this paper the columns of $0.05 \mathrm{~m}$ diameter were fed with $10 \mathrm{l} / \mathrm{d}$ wastewater flow rate and higher hydraulic loading yields higher Filtralite $P \mathrm{PO}_{4}-\mathrm{P}$ sorption [24].

At the end of the experiment the iron filings had removed $2.25 \mathrm{~g} \mathrm{PO}_{4}-\mathrm{P} / \mathrm{kg}$ filter material, which is 1.4 times more than in the case of the submerged Filtralite $P$. On the other hand, it should be taken into account that bulk density of the iron filings is 2.6 times higher than the bulk density of Filtralite $P$. When evaluating the amount of removed $\mathrm{PO}_{4}-\mathrm{P}$ per volume of filter material, it is seen that the ron filings have removed 3.3 times larger amount of $\mathrm{PO}_{4}-\mathrm{P}$ than the submerged Filtralite $P$. Accordingly, three times less filter material is needed to remove the same phosphorus amount, which is an important advantage, because this kind of wastewater treatment system requires less space. Besides, it should be also taken into account that $\mathrm{PO}_{4}-\mathrm{P}$ removal potential of the iron filings was not exhausted entirely during the experiment, thus, it can be assumed that they are able to remove even more phosphorus.

Figure 8 shows $\mathrm{PO}_{4}-\mathrm{P}$ concentration in wastewater along the height of the columns, and Table 4 provides summarized results of the experiment.

From Figure 8 it is seen that $\mathrm{PO}_{4}-\mathrm{P}$ concentration at different height of the column with iron filings is lower than of the column with submerged Filtralite $P$. Table 4 shows that in the column with iron filings amount of removed $\mathrm{PO}_{4}-\mathrm{P}$ decreased with depth of the column, while the largest $\mathrm{PO}_{4}-\mathrm{P}$ amount was removed in the top layer $(0-30 \mathrm{~cm})$ of the filter material. Adam et al. (2005) [25] while investigating Filtralite $P$ material as well as Sovik and Klove (2005) [20] investigating shellsand in horizontal flow experimental systems, they both found that the largest phosphorus amount is accumulated at the inlet of the system. While as the distance from the inlet increases, the accumulated amount of phosphorus slightly decreases. Renman (2008) [18] and Gustafsson et al. (2008) [9] investigated phosphorus removal potential of various filter materials (blast furnace slag, opoka, Polonite, limestone, wollastonite, Filtra P) in vertical columns and also came to a conclusion that phosphorus is mostly removed in the top layer of the substrate. Whereas in real wastewater treatment systems distribution of phosphorus sorbed in filter material may vary. E. g., Zhu (1998) [30] found that the largest phosphorus amount is sorbed at the inlet of the system filled with light-weight aggregate, while Adam et al. (2006) [31] experiments showed that in subsurface flow wetland filled with Filtralite $P$ material larger $\mathrm{PO}_{4}-\mathrm{P}$ amount was sorbed at the outlet. In real wastewater treatment systems different distribution of phosphorus sorbed may be explained by possible differences of parameters such as hydraulic conductivity, particle size and porosity of filter material in different points of a huge system. Therefore $\mathrm{PO}_{4}-\mathrm{P}$ sorption patterns established during column studies will not always mimic $\mathrm{PO}_{4}-\mathrm{P}$ sorption patterns in real wastewater treatment systems [24]. 


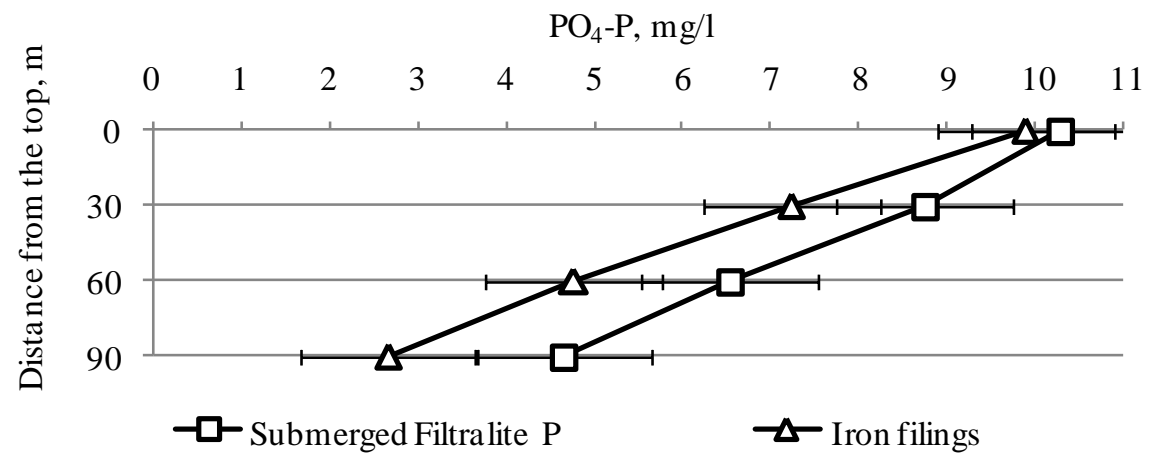

Figure 8. $\mathrm{PO}_{4}-\mathrm{P}$ profiles at different column height

\begin{tabular}{|c|c|c|c|c|}
\hline \multirow[t]{2}{*}{ Column height, $\mathrm{m}$} & \multicolumn{2}{|c|}{$\begin{array}{c}\text { Removed } \mathrm{PO}_{4}-\mathrm{P}, \% \text { of concentration } \\
\text { in the nfluent }\end{array}$} & \multicolumn{2}{|c|}{$\mathrm{PO}_{4}-\mathrm{P}$ removal efficiency, $\%$} \\
\hline & $\begin{array}{l}\begin{array}{l}\text { Filtralite } P \\
\text { submerged }\end{array} \\
\end{array}$ & - Iron filings & $\begin{array}{c}\text { Filtralite } P- \\
\text { submerged }\end{array}$ & Iron filings \\
\hline 30 & 27.2 & 36.8 & 14.9 & 26.8 \\
\hline 60 & 39.4 & 34.1 & 25.4 & 34.0 \\
\hline 90 & 33.5 & 29.2 & 28.9 & 44.1 \\
\hline
\end{tabular}

Table 4. $\mathrm{PO}_{4}-\mathrm{P}$ sorption at different column height

In the column with iron filings the $\mathrm{PO}_{4}-\mathrm{P}$ removal efficiency increased with depth of the column (Table 4): in the top layer $(0-30 \mathrm{~cm})$ it reached $27 \%$, whereas in the bottom layer $(60-90 \mathrm{~cm})$ it was even $44 \%$. The same tendency was observed in the column with Filtralite $P$; however, the $\mathrm{PO}_{4}-\mathrm{P}$ removal efficiency in all layers of this filter material was lower in comparison with the iron filings medium.

\section{CONCLUSIONS}

1. The correlation between Filtralite $P \mathrm{PO}_{4}-\mathrm{P}$ removal efficiency and $\mathrm{pH}$ value in effluent from the column was established during the experiment: both in the case of submerged and unsubmerged Filtralite $P$ the $\mathrm{PO}_{4} \mathrm{P}$ removal efficiency exceeded $90 \%$ when $\mathrm{pH}$ in the effluent was higher than 9.5 .

2. During the experiment the submerged Filtralite $P$ sorbed almost double amount of $\mathrm{PO}_{4}-\mathrm{P}$ compared to the unsubmerged Filtralite $P$ : the submerged Filtralite $P$ sorbed $1581 \mathrm{mg} \mathrm{PO}_{4}-$ $\mathrm{P} / \mathrm{kg}$ filter material $\left(662 \mathrm{mg} \mathrm{PO}_{4}-\mathrm{P} / \mathrm{m}^{3}\right.$ filter material) until its $\mathrm{PO}_{4}-\mathrm{P}$ removal efficiency became 0, while the unsubmerged Filtralite $P$ sorbed only $881 \mathrm{mg} \mathrm{PO}_{4}-\mathrm{P} / \mathrm{kg}$ filter material (369 mg $\mathrm{PO}_{4}-\mathrm{P} / \mathrm{m}^{3}$ filter material). In both cases the sorption capacity of Filtralite $P$ was higher than in the column experiments carried out by Adam et al. (2007) [3]. It can be associated with higher hydraulic loading rate as, according to [24], Filtralite $P$ sorbs larger amount of $\mathrm{PO}_{4}-\mathrm{P}$ at higher hydraulic loading rate.

3. Through the experimental period the iron filings removed $2249 \mathrm{mg} \mathrm{PO}_{4}-\mathrm{P} / \mathrm{kg}$ filter material, which is 1.4 times more than in the case of the submerged Filtralite $P$. When 
evaluating the amount of removed $\mathrm{PO}_{4}-\mathrm{P}$ per volume of filter material, the iron filings removed $2164 \mathrm{mg} \mathrm{PO}_{4}-\mathrm{P} / \mathrm{m}^{3}$ filter material, i. e. 3.3 times more than the submerged Filtralite $P$ did. Moreover, it should be also taken into account that during the experiment $\mathrm{PO}_{4}-\mathrm{P}$ removal potential of iron filings was not exhausted entirely, thus, it can be assumed that they are able to remove even more phosphorus.

4. In the case of iron filings the largest $\mathrm{PO}_{4}-\mathrm{P}$ amount was removed in the top layer $(0-30 \mathrm{~cm})$ of the filter material. The amount of removed $\mathrm{PO}_{4}-\mathrm{P}$ decreased and $\mathrm{PO}_{4}-\mathrm{P}$ removal efficiency increased with depth: in the top layer $(0-30 \mathrm{~cm}) \mathrm{PO}_{4}-\mathrm{P}$ removal efficiency was $27 \%$, whereas in the bottom layer $(60-90 \mathrm{~cm})$ it reached $44 \%$. The same tendency of $\mathrm{PO}_{4}-\mathrm{P}$ removal efficiency was observed in the column with Filtralite $P$; however, the $\mathrm{PO}_{4}-\mathrm{P}$ removal efficiency in all layers of this filter material was lower in comparison with the iron filings.

5. Iron filings are a promising material for $\mathrm{PO}_{4}-\mathrm{P}$ removal from wastewater; however, further research is needed.

\section{REFERENCES}

[1] Vohla, C., et al., 2009. Filter materials for phosphorus removal from wastewater in treatment wetlands - A review. Ecological Engineering 37(1), 70-89.

[2] Keplinger, K.O., et al., 2004. Cost and affordability of phosphorus removal at small wastewater treatment plants. Small Flows Quarterly 5(4), 36-49.

[3] Adam, K., et al., 2007. Phosphorus retention in the filter materials shellsand and Filtralite $P^{\circledR}$-Batch and column experiment with synthetic $\mathrm{P}$ solution and secondary wastewater. Ecological Engineering 29, 200-208.

[4] Arias, C.A., Bubba, M., Brix, H., 2001. Phosphorus removal by sands for use as media in subsurface flow constructed reed beds. Water Research 35(5), 1159-1168.

[5] Brix, H., Arias, C.A., del Bubba, M., 2001. Media selection for sustaianble phosphorus removal in subsurface flow constructed wetlands. Water Science and Technology 44(11), 4754.

[6] Burde, M., Rolf, F., Grabowski, F., 2001. Innovative low cost procedure for nutrient removal as an integrated element of a decentralised water management concept for rural areas. Water Science and Technology 44(1), 105-112.

[7] Camargo Valero, M.A., et al., 2009. Enhanced phosphorus removal in a waste stabilization pond system with blast furnace slag filters. Desalination and Water Treatment 4, $122-127$.

[8] Chazarenc, F., Brisson, J., Comeau, Y., 2007. Slag columns for upgrading phosphorus removal from constructed wetland effluents. Water Science and Technology 56(3), 109-115.

[9] Gustafsson, J.P., et al., 2008. Phosphate removal by mineral-based sorbents used in filters for small-scale wastewater treatment. Water Research 42, 189-197.

[10] Heal, K., et al., 2003. Novel use of ochre from mine water treatment plants to reduce point and diffuse phosphorus pollution. Land Contamination and Reclamation 11, 145-152.

[11] Hedstrom, A., 2006. Wollastonite as reactive filter medium for sorption of wastewater ammonium and phosphorus. Environmental Technology 27, 801-809.

[12] Heistad, A., et al., 2006. A high-performance compact treatment system treating domestic wastewater. Ecological Engineering 28, 374-379.

[13] Korkusuz, E.A., et al., 2005. Use of blast furnace granulated slag as a substrate in vertical flow reed beds: Field application. Bioresource Technology 98, 2089-2101. 
[14] Mortula, M. M., Cagnon, G. A., 2007. Phosphorus treatment of secondary municipal effluent using oven-dried alum residual. Journal of Environmental Science and Health 42, 1685-1691.

[15] Nelin, C. 2008. Evaluation of using fine grain size Polonite as sorbent for retaining phosphorous from wastewater. Lunds universitet. $20 \mathrm{p}$.

[16] Ozacar, M., 2003. Adsorption of phosphate from aqueous solution onto alunite. Chemosphere 51, 321-327.

[17] Rastas Amofah, L. R., Hanaeus, J., 2006. Nutrient recovery in a small scale wastewater treatment plant in cold climate. Vatten 62, 355-368.

[18] Renman, A., 2008. On-site wastewater treatment - Polonite and other filter materials for removal of metals, nitrogen and phosphorous: Doctoral Thesis. Royal Institute of Technology. 48 p.

[19] Rolf, F., Grabowski, F., Burde, M., 1998. Low cost procedure for nutrient removal in small rural wastewater treatment plants. Water Science and Technology 38(3), 179-185.

[20] Sovik, A.K., Klove, B., 2005. Phosphorus retention processes in shell sand filter systems treating municipal wastewater. Ecological Engineering 25, 168-182.

[21] Cucarella, V., Renman, G., 2009. Phosphorous sorption capacity of filter materials used for on-site wastewater treatment determined in batch experiments. Journal of Environmental Quality 38, 381-392.

[22] Hedstrom, A., 2006. Reactive filter systems for small scale wastewater treatment. Vatten $62,253-263$.

[23] Johansson Westholm, L., 2006. Substrates for phosphorus removal - Potential benefits for on-site wastewater treatment? Water Research 40, 23-36.

[24] Adam, K., et al., 2007. Phosphorus removal by the filter materials light-weight aggregates and shellsand - A review of processes and experimental set-ups for improved design of filter systems for wastewater treatment. Vatten 62, 245-257.

[25] Adam, K., et al., 2005. Phosphorous sorption by Filtralite $P$ - Small scale box experiment. Journal of Environmental Science and Health 40, 1239-1250.

[26] Jenssen, P.D., Krogstad, T., 2003 Design of constructed wetlands using phosphorus sorbing lightweight aggregate (LWA). In: Constructed Wetlands for Wastewater Treatment in Cold Climates. WIT Press, Southampton, pp. 259-271.

[27] Kang, S.-K., Choo K.-H., Lim, K.-H., 2003. Use of iron oxide particles as adsorbents to enhance phosphorus removal from secondary wastewater effluent. Separation Science and Technology 38(15), 3853-3874.

[28] Choung, Y.K., Jeon, S.J., 2000. Phosphorus removal in domestic wastewater using anaerobic fixed beds packed with iron contactors. Water Science and Technology 41(1), 241244.

[29] Product Specification of Filtralite Filter Media. [online]. 2012. Available from: <http://www.filtralite.com/media/92/datasheets/Datablad_Filtralite_P_0-4.pdf>. [2012 04 17].

[30] Zhu, T., 1998. Phosphorus and nitrogen removal in light-weight aggregate (LWA) constructed wetlands and intermittent filter systems: PhD Thesis. Agricultural University of Norway.

[31] Adam, K., Sovik, A.K., Krogstag, T., 2006. Sorption of phosphorus to Filtralite P - The effect of different scales. Water Research 40, 1143-1154. 